\title{
Asymmetric Effects in Emerging Stock Markets- The Case of Iran Stock Market
}

\author{
Seyyed Ali Paytakhti Oskooe (Corresponding author) \\ School of Economics, Kingston University \\ London KT1 2EE, UK
}

Tel: 44-(0)20-8417-9000Ｅ-mail: k0851485@kingston.ac.uk

\author{
Ali Shamsavari \\ School of Economics, Kingston University \\ London KT1 2EE, UK
}

Tel: 44-(0)20-8417-9000Ｅ-mail: a.shamsavari@kingston.ac.uk

Received: May 25, 2011

Accepted: June 6, 2011

Published: November 1, 2011

doi:10.5539/ijef.v3n6p16

URL: http://dx.doi.org/10.5539/ ijef.v3n6p16

\begin{abstract}
In view of the mixed empirical results in the literature, this paper assesses the extent of asymmetric volatility effects in the Iranian stock market as an emerging stock market, using a variety of nonlinear autoregressive conditional heteroskedasticity specifications. Tests based on standardized residuals from a fitted GARCH model suggest a lack of asymmetric effects in the dynamic volatility of the Iranian stock market. Empirical analyses with asymmetric GARCH models also reject the hypothesis of asymmetric volatility, in contrast to most developed and emerging markets. Hence, good and bad news of the same magnitude have similar impacts on the volatility level in the Iranian stock market. The leverage effect modified by inflation advantage and price limit may be the main reasons for lack of asymmetric effect in emerging stock markets.
\end{abstract}

Keywords: Nonlinear GARCH models, Asymmetric effect, Inflation advantage, Price limit

\section{Introduction}

It is generally believed that in stock markets positive and negative shocks may affect the volatility of stock returns differently; more specifically, volatility responds more to negative shocks (bad news) than to positive shocks (good news). In other words, there may be negative correlation between the current stock return and future volatility. Generally speaking, stock market volatility tends to be greater in a falling market than in a rising market. This behavior of stock returns in response to new information flow is known as asymmetric volatility. Engle (2004) in his Nobel Laureate lecture, using data for the S\&P 500, demonstrates that asymmetric volatility has a significant impact on stock market risk and asserts that ignoring asymmetry in volatility leads to a significant underestimation of the Value at Risk (VaR). Recognition of the presence of asymmetric volatility is important to portfolio selection, risk management, hedging strategies and the pricing of financial derivatives such as options and futures. It is also the case that as asymmetric volatility increases market risk, its magnitude should concern individual investors, investment fund managers, and government policymakers. In theoretical and empirical literature, there are various explanations for asymmetric behavior of stock returns. The popular explanation for the presence of asymmetric volatility in stock markets is leverage effect. According to Black (1976) and Christie (1982), a stock price fall reduces the value of equity and hence increases the debt-to-equity ratio. This increase in leverage raises the riskiness of the firm and leads to higher levels of volatility. Under these circumstances, shareholders who bear the residual risk of the firm recognize that their future cash-flow stream is relatively more risky. Pindyck (1984) and Campbell and Hentschel (1992) propose "volatility feedback" as another explanation for asymmetric volatility effects. In this sense, increases in volatility raise the desired stock returns and cause an immediate price decline. In other words, since volatility is a measure of risk, an increase in volatility signals a higher risk and also higher expected future risk. To bear this risk, investors will require higher returns and are thus inclined to pay less for the relevant equity. Stock trading activity is suggested as another reason for asymmetric effects (Avramov et. at (2004)). In this explanation, uninformed traders sell when stock prices fall, leading to an increase in stock returns volatility, while informed investors sell after stock price rises, which leads to a decline in volatility. 
An understanding of the volatility dynamic of emerging stock markets has been a major issue in the empirical literature. Even though the asymmetric volatility phenomenon is well documented in developed and emerging stock markets, there is some evidence indicating lack of asymmetric behaviour particularly in emerging stock markets (Rousan and Al-khouri (2005), Brooks (2007), Mun et al (2008), Bahadur (2008), Alagidede and Panagiotidis (2009), Jayasuriya et al (2009) and Cheng et al (2010)). Mehrara and Abdoli (2006) using the time-varying volatility model and employing the daily Iranian stock market index over the period of March 301999 to May 52003 shows that responses of stock returns to good and bad news are symmetric. They propose the slow flow of information and infrastructural restrictions as reasons for the lack of asymmetric effects in the Iranian stock market. However, research by Abounoori and Motameni (2007) covers a longer period and achieves different conclusions. They applied a Latent VAR model to examine volatility feedback theory in the Iranian stock market, employing the daily Iranian stock market index during Jan 11992 to Jun 30 2006. They found that contrary to the volatility feedback theory the anticipated volatility has no direct effect on the stock returns. More recently, Saeidi and Koohsarian (2010), applying the exponential GARCH (EGARCH) model to the monthly stock market index concluded the presence of asymmetry of volatility and leverage effects in the Iranian stock market. In the light of these mixed results regarding asymmetric effect in the literature, we are going to examine the asymmetric volatility hypothesis using a novel method and fresh data in an emerging stock market, namely Iran. In this article since financial time series display stylized facts e.g. fat tails, high peakedness, skewness, volatility clustering and non-normal distribution and in view of the fact that GARCH specifications are capable of capturing these characteristics, to estimate the possible asymmetric volatility, we model asymmetric volatility in the conditional variance equation of the time-varying volatility model.

The reminder of the paper is organized as follows: section 2 outlines and explains the research methodology; the data and empirical results are discussed in section3. The paper concludes by summarizing the main conclusions.

\section{Methodology}

In order to examine the presence of asymmetric effects (volatility-return correlation) in the Iranian stock market, we first analyze the dynamics of stock returns volatility. To this end, we apply the Generalised Autoregreressive Conditional Heteroskedasticity (GARCH) model. In the volatility modeling process using GARCH models, the first moment (mean) and second moment (variance) of the series are estimated simultaneously. A GARCH model for stock returns, assuming that the distribution of the return series for period $t$, conditional on all previous returns (or information), is normal with constant mean $\boldsymbol{\mu}$ and time-varying conditional variance $\boldsymbol{h}_{\mathrm{t}}$, can be expressed as:

$$
r_{t}=E_{t-1}\left(r_{t}\right)+\varepsilon_{t}, \varepsilon_{t} \sim N I D\left(0, h_{t}\right)
$$

Where $E_{t-1}($.$) represents expectation based on information available at time t-1, and \varepsilon_{t}=Z_{t} \sqrt{h_{t}}$, where $Z_{t}$ is i.i.d with zero mean and unit variance .

The conditional variance equation in $\operatorname{GARCH}(\mathrm{p}, \mathrm{q})$ process can be expressed as:

$$
h_{t}=\omega+\sum_{i=1}^{p} \alpha_{i} \varepsilon_{t-i}^{2}+\sum_{j=1}^{q} \beta_{j} h_{t-j}
$$

The non-negativity restrictions are $\boldsymbol{\omega}>0, \alpha_{i}>0$ and $\beta_{i} \geqslant 0$. The condition $\sum_{i=1}^{q} \alpha_{i}+\sum_{j=1}^{p} \beta_{j} \prec 1$ implies that the GARCH process is weakly stationary since the mean, variance, and autocovariance are finite and constant over time. The $\alpha_{i}$ represents the short-run persistence of shocks, while the $\beta_{i}$ implies the long-run persistence. In this sense, the size and significance of $\alpha_{i}$ implies the existence of the ARCH process in the error term (volatility clustering).

To detect asymmetric volatility in the stock return series, Engle and $\mathrm{Ng}$ (1993) proposed a set of tests, known as sign and bias tests. These tests should be used to investigate whether an asymmetric GARCH model is required for stock return series. In volatility modeling of the stock return series, the diagnostic Engle-Ng tests are used to detect misspecifications related to asymmetric effects, based on the residuals of a GARCH model fitted to the stock return series. The underlying idea is that, if the volatility process is correctly specified, then the squared standardized residuals should not be predictable on the basis of observed variables. These tests can be individually computed from the following equations:

$$
\text { a) Sign bias t-test: } \quad \widehat{\varepsilon}_{t}^{2}=\phi_{0}+\phi_{1} S_{t-1}^{-}+e_{t}
$$

$$
\text { b) Positive size bias t-test: } \quad \widehat{\varepsilon}_{t}^{2}=\phi_{0}+\phi_{1} S_{t-1}^{-} \varepsilon_{t-1}+e_{t}
$$

c) Negative size bias t-test: $\widehat{\mathcal{E}}_{t}^{2}=\phi_{0}+\phi_{1}\left(1-S_{t-1}^{-}\right) \varepsilon_{t-1}+e_{t}$

d) Joint test for three effects: $\widehat{\varepsilon}_{t}^{2}=\phi_{0}+\phi_{1} S_{t-1}^{-}+\phi_{2} S_{t-1}^{-} \varepsilon_{t-1}+\phi_{3}\left(1-S_{t-1}^{-}\right) \varepsilon_{t-1}+e_{t}$

Where $\varepsilon_{t}$ is the error term under the null hypothesis, $S_{t-1}^{-}$is dummy variable that takes the value of one when 
$\boldsymbol{E}_{t-1}<0$ and zero otherwise. The sign bias test examines the impact of positive and negative innovations on volatility not predicted by GARCH model. Significance of $\phi_{1}$ in the first equation indicates that positive and negative shocks have differing impacts on future volatility. The positive size test examines how well the model captures the impact of large and small positive shocks. On the other hand, the negative size test verifies the efficiency of the fitted model in the capture of large and small innovations. The null hypothesis of no asymmetric effects, $\mathrm{H}_{0}: \phi_{1}=\phi_{2}=\phi_{3}=0$, is tested with an LM test which asymptotically follow a $\chi^{2}$ distribution with 3 degrees of freedom.

Another simple procedure to detect leverage effect in the stock returns volatility process is proposed by Enders (2004). In this method the null hypothesis that there are no leverage effects is tested by estimating the following regression equation:

$$
\varepsilon_{t}^{2}=\alpha_{0}+\alpha_{1} \varepsilon_{t-1}+\alpha_{2} \varepsilon_{t-2}+\ldots
$$

The underlying idea in this method is that the squared residuals should be uncorrelated with the level of the error terms when there are no leverage effects. The null hypothesis $H_{0}: \alpha_{1}=\alpha_{2}=\ldots=0 \quad$ is tested with $\boldsymbol{F}$-statistic. If the sample value of $\boldsymbol{F}$ for the null hypothesis exceeds the critical value from $\boldsymbol{F}$ table, it can be concluded there are leverage effects (asymmetric effects).

One of the significant weaknesses in the basic GARCH model is its premise of symmetric response of stock returns volatility to positive and negative shocks. This weakness is due to the fact that conditional variance in the basic model is a function of the (squared) magnitudes of the lagged residuals, regardless of their signs. In order to capture the asymmetric effect in modeling the stock returns volatility, three extensions of the basic GARCH model can be used, among other possibilities: the Threshold Autoregressive Conditional Heteroskedasticity (TARCH), the Exponential Generalized Autoregressive Conditional Heteroskedasticity $(E G A R C H)$ and the power GARCH model (PARCH) models.

The EGARCH as the non-linear GARCH model was proposed by Nelson (1991), allowing the conditional variance to depend on both the size and the sign of the lagged residuals. This model allows for the possibility of asymmetric effects between positive and negative stock returns.

$$
\operatorname{Ln}\left(h_{t}\right)=\omega+\sum_{j=1}^{q} \beta_{j} h_{t-j}+\sum_{i=1}^{p} \alpha_{i}\left|\frac{\varepsilon_{t-i}}{h_{t-i}}\right|+\sum_{k=1}^{r} \gamma_{k} \frac{\varepsilon_{t-k}}{h_{t-k}}
$$

The presence of asymmetric leverage effect is tested by the hypothesis that $\gamma_{k}<0$. The shock is symmetric if $\gamma_{k}=0$, then a positive return shock has the same effect on volatility as the negative return shock of the same amount. If $\gamma_{k} \prec 0$, positive return shocks generate less volatility than negative return shocks. On the other hand, if $\gamma_{k}>0$, positive return shocks generate more volatility than negative return shocks. The persistence of shocks to the volatility is given by $\beta$. The advantage of using the logarithmic construction on the EGARCH model is that the conditional variance will be positive, so there will be no need to impose a restriction of non-negative coefficients.

Another way to capture asymmetry effect in financial time series is modification of the original GARCH model using a dummy variable. On this basis, Glosten, Jagannathan and Runkle (1993) introduced the following TARCH model for the conditional variance:

$$
h_{t}=\omega+\sum_{i=1}^{p} \alpha_{i} \varepsilon_{t-i}^{2}+\sum_{j=1}^{q} \beta_{j} h_{t-j}+\sum_{k=1}^{r} \gamma_{k} \varepsilon_{t-k}^{2} I_{t-k}^{-}
$$

Where $I_{t}^{-}=1$ if $\varepsilon_{t}<0$ and $I_{t}^{-}=0$ otherwise.

In this specification, the effects of good and bad news on the conditional variance are completely different. The good news $\left(\varepsilon_{t-i}>0\right)$ has an impact $\alpha_{i}$, while the bad news has an impact of $\alpha_{i}+\gamma_{k}$. If $\gamma_{k>0}$, bad news enhances volatility and we can conclude the presence of leverage effect in the stock market. On the other hand, if $\gamma_{k} \neq 0$, the news (shocks) impact is asymmetric. $\beta_{j}$ measures the persistence of the conditional variance, the sum of $\alpha_{i}+\beta_{j}+\gamma_{k} / 2$ represents the persistence of shocks on volatility. If the sum is less than one then the shock is not expected to last for a long time, if it is close to one means that the shock will affect volatility and the volatility can be predicted for some time. However, if the sum of the coefficients is one then shock is going to affect volatility for the indefinite future.

Using power transformations parameter Ding et al. (1993) proposed the power GARCH model (PARCH $(1,1,1))$ to capture asymmetric effect. This asymmetric GRCH model has the form:

$$
h_{t}=\omega+\sum_{i=1}^{p} \alpha_{i}\left(\left|\varepsilon_{t-i}\right|-\gamma_{i} \varepsilon_{t-i}\right)^{d}+\sum_{j=1}^{q} \beta_{j} h^{d-j}
$$

This model allows an optimal power term to be estimated from the data (instead of being pre-specified as in the 
GARCH and EGARCH). In other words, the introduction of the power d increases the flexibility of GARCH-type models, and avoids a priori selection of an arbitrary. In addition, this model includes a leverage parameter to capture volatility asymmetry. The power term (d) captures both the conditional standard deviation $(\mathrm{d}=1)$ and conditional variance $(d=2)$ as special cases. The asymmetry effect in the model is captured via the parameter $\gamma_{i}$.

\section{Data and Empirical Results}

In order to examine the asymmetric effect, we use the daily closing price of the Iranian stock market weighted index (based on company's shares number), from January 2, 1999 to December 30, 2009, with a total of 2632 observations. Market prices index are transformed to daily returns $r=\ln \left(p_{t} / p_{t-1}\right)$ where $p_{t}$ and $p_{t-1}$ are stock prices index prices at date $t$ and $t-1$ respectively.

The model-building process should take into account the special properties (the salient features) of financial data or statistical illusions of stock returns to achieve reasonable analysis. In other words, analyzing the distribution of characteristics of stock prices or stock returns is crucial in investigation of the behavior of stock prices, correct model specification, estimation and forecasting. In order to be able to analyze the distributional characteristics of stock return series in the Iranian stock market and understanding information about a probability distribution function of stock returns, measures of location (mean), dispersion (variance, and standard deviation), asymmetry(skewness) and concentration in tails (kurtosis) are calculated. The parameters mean and variance signify the standardized first and second moments of a distribution, the skewness as the standardized third moment measures the asymmetry of a distribution and the kurtosis as the central fourth moment determines the degree of peakedness and tail fatness of a distribution.

Table 1 provides the descriptive statistics (the unconditional distribution statistics) for Iran stock returns. The wide gap between the maximum (5.2581\%) and minimum (-5.4330\%) returns gives support to the high variability of price change in the Iranian stock market. In the same way, the high standard deviation with respect to the mean is an indication of the high volatility in the Iranian stock market and the risky nature of the market. A visual analysis of the market volatility can be seen in Figure 1. The mean of stock return series is constant, while the variance keeps changing over time. The large changes (of either sign) in stock returns tend to be followed by large changes, and small movements (of either sign) being followed by small movements. This is a property of stock returns distribution known as volatility clustering or volatility pooling (a type of heteroscedasticity) that Iran stock return series seems to exhibit. The implication of volatility clustering is that volatility shocks today will influence the expectation of volatility in some periods in the future. In these circumstances, the current level of volatility tends to be positively correlated with its level during the immediately preceding periods. Positive skewness means that the Iran stock returns distribution is skewed to the right of its mean and has a long right tail. This means that in the Iranian stock market large positive returns tend to occur more often than large negative ones. In other words, large positive movements in stock prices are not usually matched by equally large negative movements. Accordingly, the distribution of Iran stock return series is non- symmetric. In other words, the stock returns distribution is the asymmetric to the right with a few extreme and positive values. At the same time, the kurtosis or degree of excess, in the Iran stock returns series is bigger than the normal value of 3 . As a result, the distribution of Iran stock returns is peaked_leptokurtic.

It is worth highlighting that with regard to the skewness and the kurtosis statistics of Iran stock returns it can be concluded that the distribution of stock returns departs from normal distribution. Furthermore, according to the calculated Jarque-Bera statistics and corresponding p-value in table 1, the stock return series is not well approximated by the normal distribution. Generally speaking, in line with the findings of other empirical studies in emerging stock markets, Iran stock return time series are characterized by some "stylized fact" such as fat tails, high peakness (excess kurtosis), skewness and volatility clustering.

Since Iran stock return series do not follow normal distribution, the GARCH models are estimated with the GED (Generalized Error Distribution) which takes into account the fat tail characteristic of stock returns distribution. We have examined several GARCH models and according to the results of diagnostic tests (residual test) on mean and variance equations as well as BIC criteria we conclude that the ARIMA $(9,8)-\operatorname{GARCH}(1,1)$ model is most likely to succeed in describing the Iran stock return generating process. (Note 1).Table 2 displays the results of the estimation of ARIMA $(9,8)$-GARCH $(1,1)$ model. As has been noted above, the estimated ARIMA $(9,8)$ - GARCH $(1,1)$ models cannot detect asymmetric volatility in the dynamic of stock returns.

After specifying the mean and variance equations, we have examined the existence of asymmetry in stock returns volatility to investigate different effects of positive or negative shocks on the structure of stock market volatility. To this end, we apply the Engle and $\mathrm{Ng}$ (1993) and Enders (2010) asymmetric effect tests on the standardized residuals of ARMA $(9,8)$ - GARCH $(1,1)$ model. As shown in table 3 , since the probability associated with test statistic is 
greater than 0.05 , the conventional level of significance, we can conclude the sign bias coefficient is insignificant implying the ability of estimated GARCH model in predicting the impact of positive and negative innovations on stock market volatility. Furthermore, in view of the prob-value $(0.2917)$ the result from negative size bias test signifies that there is no negative sign bias in the Iranian stock market. In other words, the fitted GARCH model well captures the impact of large and small innovations. However, there is positive size bias in the residuals of estimated GARCH model but it is statistically insignificant. While the estimated coefficient for positive size bias is -0.0279 , the prob-value is 0.8638 ; we can reject the null hypothesis that the positive shocks have different effect on future volatility. At the same time, the sample LM statistic for the null hypothesis is 1.3335 with three degree of freedom, the prob-value is 0.7212 , and we can conclude that there is not asymmetric effect in Iran stock return behavior. On the whole, the joint test on the residuals from the ARMA $(9,8)-\operatorname{GARCH}(1,1)$ model cannot reject the null of symmetry for the Iranian stock market. To put it another way, the volatility of the Iranian stock market is symmetric and there is not asymmetric effect in the stock return response to new information. However, as Engle and $\mathrm{Ng}$ (1993) argue, the joint test is more powerful than the individual tests. In the same way, Zivot (2009) argued that the negative value of sample correlation between $r_{t}^{2}$ and $r_{t-1}$ provides some evidence for potential asymmetric effect. As shown in table 3, the correlation between $r_{t}^{2}$ and $r_{t-1}$ is positive indicating strong evidence for the lack of asymmetric effect in the dynamic of Iran stock return series.

In order to investigate leverage effects (asymmetric effects) in the Iran stock return series, we use also the Enders (2004) procedure. Table 4 displays the results from regressing the squared standardized residuals on the lagged levels of error terms from fitted GARCH model. According to reported results in table 4, the sample F-statistic for the null hypothesis is 0.2420 and less than the critical value obtained from an F table, it can be noted that there is no asymmetric effect in the dynamic volatility of the Iranian stock market. In other words, in Iran stock return data generating process the squared standardized residuals are not predictable on the basis of observed variables.

In spite of the results of the Engle and $\mathrm{Ng}$ (1993) and Enders (2010) asymmetric effect tests indicating lack of asymmetric effect in data generating process of Iran stock returns, we apply three asymmetric GARCH models (TGARCH(1,1),EGARCH(1,1), PARCH(1,1,1)). Table 1 demonstrates the results of the application of these models to the Iran stock return series. Since the probabilities are greater than the conventional level of significance $5 \%$, the asymmetry term $(\gamma)$ in three models is statistically insignificant. In other words, there is no significant asymmetric effect in the Iran stock returns series. As such, it can be noted that there is no asymmetric volatility in the Iran stock return series. In view of this finding, it can be highlighted that in the Iranian stock market investors do not overreact (underreact) to bad news and underreact (overreact) to good news. Therefore, we conclude that the response to the stock returns shocks is not asymmetrical in the Iranian stock market and the variance equation of GARCH $(1,1)$ model is well specified.

An important implication of these findings is that the good news and bad news have the same effects on stock prices in the Iranian stock market. In this sense, stock prices reflect symmetrically new information. It can be noted that in the Iranian stock market correlation between changes in stock prices (unexpected returns) and changes in stock returns volatility is not negative. Under these circumstances, there is tendency for stock returns volatility to increase when stock returns rise and to decline when stock returns fall. It can be noted that in this market bad news (negative shocks) increase volatility equal to good news (positive shocks). In view of the more popular reason (leverage effect) for the presence of asymmetric effect, the potential explanation derives from "inflation advantage". In inflationary conditions (specifically in developing countries) the long term debts are considered an advantage to the firm. Under this circumstance, increasing debt to assets ratio (leverage) does not lead to higher stock volatility (risk) in stock market. In other words, in an inflationary economy an increase in the leverage ratio is not considered a risk criterion for firms. Additionally, the "price limit" which is introduced especially in emerging markets to control market volatility can be another reason for the lack of asymmetric effect. It seems that in this circumstance the reaction amplitude of stock prices to new information is reduced.

\section{Conclusion}

Motivated by theoretical background and empirical literature, this paper examines the asymmetric volatility hypothesis based on the stock returns data generating process. In order to verify the asymmetric effect, firstly we apply the Engle and $\mathrm{Ng}$ (1993) and Enders (2010) asymmetric tests on the standardized residuals from fitted ARIMA - GARCH $(1,1)$ model. Results indicate that there is no asymmetric effect in the volatility dynamic. On the other hand, the empirical results from estimating asymmetric GARCH models (TARCH, EGARCH and PARCH) do not confirm the asymmetric volatility in Iran stock returns data generating process.

This finding is in contrast to results from other studies for emerging or developed stock markets. For instance, Liu et al (2009) for China, Nowbutsing and Naregadu (2009) for Mauritius, Hung (2009) for Taiwan, Charles (2010) for 
France, Germany, US and Japan, Cheng et al. (2010) for Bahrain, Kuwait, Oman, Saudi Arabia, Egypt, Jordan and Turkey, Krishnan and Mukherjee (2010) for India, Sabiruzzaman et al (2010) for Hong Kong and Tan and Islam Khan (2010) for Malaysia stock markets find out the existence of leverage effects in volatility modelling. On the other hand, this finding is not unique to our study as many other studies have reached similar conclusions (Rousan and Al-khouri (2005) for Amman, Brooks (2007) for Chilli, Saudi Arabia and Bahrain, Mun et al. (2008) for Malaysia, Bahadur (2008) for Nepal, Alagidede and Panagiotidis (2009) for Tunisia and Zimbabwe, Jayasuriya et al. (2009) for Brazil, Chile, Indonesia, Pakistan and Taiwan, Saeidi and Koohsarian (2010) for The Iranian stock market, Cheng et al. (2010) for Morocco, Charles (2010) for the UK stock markets). On the whole it can be noted that the asymmetric volatility (negative relationship between stock returns movements and future volatility) is not applicable to Iran market as an emerging stock market. In other words, positive and negative shocks (good and bad news) of the same magnitude have the same impact and effect on the future volatility level. Since the asymmetric volatility is one of the effective factors in portfolio selection, asset pricing, option pricing and hedging strategies, this finding has important implications for investment process in emerging stock market specifically the Iranian stock market.

\section{References}

Abounoori, E. Motameni, M. (2006). Simultaneous Effects of Leverage and Volatility Feedback in Tehran Stock Exchange (In Farsi). Tahghighat-e-Eghtesadi, 76, 101-17. Available at: http://www.sid.ir/en/JournalList.asp?ID=2353\&Name=TAHGHIGHAT\%2DE\%2DEGHTESADI

Alagidede, P. Panagiotidis, T. (2009). Modelling stock returns in Africa's emerging equity markets. International Review of Financial Analysis, 18, 1-11. http://dx.doi.org/10.1016/j.irfa.2009.02.001

Avramov, D. Chordia, T. Goyal, A. (2006). The Impact of Trades on Daily Volatility. The Review of Financial Studies, 19, 1241-1277. http://dx.doi.org/10.1093/rfs/hhj027

Bahadur, S. (2008). Volatility Analysis of Nepalese Stock Market. The Journal of Nepalese Business Studies, 4(1), 76-84.

Black, F. (1976). Studies of Stock, Price Volatility Changes, Proceedings of the 1976 Meetings of the Business and Economics Statistics Section. American Statistical Association, 177-81.

Brooks, R. (2007). Power arch modelling of the volatility of emerging equity markets. Emerging Markets Review, 8(2), 124-133. http://dx.doi.org/10.1016/j.ememar.2007.01.002

Campbell, J. L. Hentschel. (1992). No News Is Good News, Journal of Financial Economics. 31(3), 281-318. http://dx.doi.org/10.1016/0304-405X(92)90037-X

Charles, A. (2010). The day-of-the-week effects on the volatility: The role of the asymmetry. European Journal of Operational Research, 202, 143-152. http://dx.doi.org/10.1016/j.ejor.2009.04.022

Cheng, A.R. Jahn-Pavar, M.R. Rothman, P. (2010). An empirical investigation of stock market behaviour in the Middle East and North Africa. Journal of Empirical Finance, 17, 413-427. http://dx.doi.org/10.1016/j.jempfin.2009.11.002

Christie, A. (1982). The Stochastic Behaviour of Common Stock Variances: Value, Leverage and Interest Rate Effects. Journal of Financial Economics, 10(4), 407-32. http://dx.doi.org/10.1016/0304-405X(82)90018-6

Enders,W. (2010). Applied Econometric Time Series, third edition, .Hoboken, NJ: John Wiley\& Sons LTD.

Engle, R. F. (1982). Autoregressive Conditional Heteroskedasticity with Estimates of the Variance of U.K. Inflation. Econometrica, 50, 987-1008. http://dx.doi.org/10.2307/1912773

Engle, R.F. Ng, V.K. (1993) Measuring and testing the impact of news on volatility. Journal of Finance, 48, 1749-1801. http://dx.doi.org/10.2307/2329066

Engle, R. (2004) Risk and Volatility: Econometric Models and Financial Practice. American Economic Review, 94 (3), 405-20. http://dx.doi.org/10.1257/0002828041464597

Glosten, L. R. Jaganathan, R. Runkle, D. (1993). On the Relation between the Expected Value and the Volatility of the Normal Excess Return on Stocks. Journal of Finance, 48, 1779-1801. http://dx.doi.org/10.2307/2329067

Hung, S. (2009). Threshold and Leverage Effects of Major Asian Stock Markets Based on Stochastic Volatility Models. International Research Journal of Finance and Economics, 27, 106-116.

Jayasuriya, S. Shambora, W. Rossemary, R. (2009). Asymmetric Volatility in Emerging and Mature Markets. Journal of Emerging Market Finance,8(1),25-43. http://dx.doi.org/10.1177/097265270900800102

Krishnan, R. Mukherjee, C., (2010). Volatility in Indian Stock Markets: A Conditional Variance Tale Re-told. 
Journal of Emerging Market Finance, 9(1), 71-93. http://dx.doi.org/10.1177/097265271000900104

Mehrara, M. Abdoli, G. (2006). The Asymmetry of Stock Market Volatility: The Case of Iran (In Farsi). Quarterly Iranian Economic Research, 26, 25-40. http://www.atu-economics.com/en/journal/

Mum, H.W. Sundaran, L. Yin, O.S. (2008). Leverage Effect and Market Efficiency of Kuala Lumpur Composite Index. International Journal of Business and Management, 3(4), 138-144.

Nelson, D. B. (1991). Conditional Heteroskedasticity in Asset Returns: A New Approach. Econometrica, 59, 347-370. http://dx.doi.org/10.2307/293826

Nowbutsing, B.M Naregadu, S. (2009). Returns, trading volume and volatility in the stock market of Mauritius. African Journal of Accounting, Economics, Finance and Banking Research, 5(5), 1-36.

Pindyck, R. S. (1984). Risk, Inflation and the Stock Market. The American Economic Review, 74 (3), 335-351.

Sabirruzzaman, Md. Huq, M. Beg, R.A. Anwar, S. (2010). Modeling and forecasting trading volume index: GARCH versus TGARCH approach. The Quarterly Review of Economics and Finance, 50, 141-145. http://dx.doi.org/10.1016/j.qref.2009.11.006

Saeidi, P. Koohsarian, A. (2010). The Investigation of the Relationship between Inflation Indexes and Stock Return in Tehran Stock Exchange (In Farsi). Tahghighat-e-Eghtesadi, 44(89), 109-128. http://www.sid.ir/en/JournalList.asp?ID=2353\&Name=TAHGHIGHAT\%2DE\%2DEGHTESADI

Tan, S.H. Islam Khan, M.T. (2010). Long Memory Features in Return and Volatility of the Malaysian Stock Market. Economics Bulletin, 30(4), 3267-3281.

Rousan, R . Al-khouri, R. (2005). Modelling Market Volatility in Emerging Markets: the case of daily data in Amman stock exchange 1992-2004. International Journal of Applied Econometrics and Quantitative Studies, 2(4), 99-118.

Zivot, E. (2009). Practical Issues in the Analysis of Univariate GARCH Models, Handbook of financial time series, Torben, G.A, A.D, Richard, J.P, Kreib and Mikosch, T, Springer.

\section{Notes}

Note1:In order to model the mean of Iran stock return series based on the autocorrelation and partial correlation of the residual of estimation of equation (1) we firstly started with $\operatorname{ARMA}(1,1)$ model and based on LB test-statistic the $\operatorname{ARMA}(9,8)$ has been selected. The estimates of low order ARMA models are available upon request.

\section{Appendices}

Table1. Descriptive statistics for Iran stock returns

\begin{tabular}{|c|c|}
\hline Mean (\%) & 0.0756 \\
\hline Median (\%) & 0.0592 \\
\hline Minimum (\%) & -5.4330 \\
\hline Maximum (\%) & 5.2581 \\
\hline Standard Deviation (\%) & 0.5169 \\
\hline Skewness (S) & 0.5595 \\
\hline Kurtosis (k) & 25.9423 \\
\hline Jarque-Bera Statistic & 57838.40 \\
\hline P-value & $(0.0000)$ \\
\hline Observation & 2631 \\
\hline
\end{tabular}


Table 2. The estimation results of ARIMA - GARCH $(1,1)$, ARIMA -TGARCH $(1,1)$, ARIMA -EGARCH $(1,1)$ and ARIMA -PGARCH $(1,1,1)$

\begin{tabular}{|c|c|c|c|c|c|c|c|c|}
\hline Coefficient & \multicolumn{2}{|l|}{ ARIMA -GARCH(1,1) } & \multicolumn{2}{l}{ ARIMA-EGARCH(1,1) } & \multicolumn{2}{l}{ ARIMA -TGARCH(1,1) } & \multicolumn{2}{l}{ ARIMA -PGARCH(1,1,1) } \\
\hline & & P-value & & P-value & & P-value & & P-value \\
\hline $\boldsymbol{\mu}$ & 0.0007 & 0.0000 & 0.0006 & 0.0000 & 0.0007 & 0.0000 & 0.0007 & 0.0000 \\
\hline $\mathrm{AR}(1)$ & 0.7375 & 0.0000 & 0.6807 & 0.0000 & 0.7348 & 0.0000 & 0.7401 & 0.0000 \\
\hline $\mathrm{AR}(9)$ & 0.0429 & 0.0000 & 0.0462 & 0.0000 & 0.0431 & 0.0000 & 0.0413 & 0.0000 \\
\hline $\mathrm{MA}(1)$ & -0.2864 & 0.0000 & -0.1836 & 0.0000 & -0.2839 & 0.0000 & -0.2941 & 0.0000 \\
\hline $\mathrm{MA}(3)$ & -0.0554 & 0.0023 & -0.0361 & 0.0275 & -0.0543 & 0.0026 & -0.0554 & 0.0020 \\
\hline $\mathrm{MA}(8)$ & 0.0210 & 0.0314 & 0.0308 & 0.0018 & 0.0214 & 0.0258 & 0.0210 & 0.0304 \\
\hline $\boldsymbol{\omega}$ & $2.30 \mathrm{E}-06$ & 0.0000 & -2.4996 & 0.0000 & $2.38 \mathrm{E}-06$ & 0.0000 & 0.0001 & 0.3382 \\
\hline $\boldsymbol{\alpha}$ & 0.4863 & 0.0000 & 0.5721 & 0.0000 & 0.5307 & 0.0000 & 0.4068 & 0.0000 \\
\hline $\boldsymbol{\beta}$ & 0.4909 & 0.0000 & 0.8130 & 0.0000 & 0.4811 & 0.0000 & 0.5739 & 0.0000 \\
\hline$\gamma$ & & & 0.0237 & 0.4460 & -0.0719 & 0.4929 & -0.0247 & 0.6834 \\
\hline
\end{tabular}

Note: $\boldsymbol{\alpha}, \boldsymbol{\beta}, \boldsymbol{\gamma}$ are the $\mathrm{ARCH}, \mathrm{GARCH}$ and asymmetry parameters respectively.

Table 3. Test for Asymmetry (Engle and Ng (1993) test)

\begin{tabular}{|c|c|c|c|c|}
\hline Corr $\left(\boldsymbol{r}_{t}^{2}, \boldsymbol{r}_{t-1}\right)$ & Sign bias test & Negative size bias test & Positive size bias test & Joint test \\
& & & & F-test, $\boldsymbol{\chi}_{(3)}^{2}$ \\
\hline 0.1747 & -0.0840 & 0.1467 & -0.0279 & 1.3335 \\
& $(0.6805)$ & $(0.2917)$ & $(0.8638)$ & $(0.7212)$ \\
\hline
\end{tabular}

Notes: p-values are shown in ()

Table 4. Test for leverage effect (Enders method)

\begin{tabular}{|c|c|c|c|}
\hline intercept & $\mathcal{E}_{t-1}$ & $\mathcal{E}_{t-2}$ & F-statistics \\
\hline 1.1686 & 0.0583 & 0.0307 & 0.2420 \\
$(0.0000)$ & $(0.5377)$ & $(0.7456)$ & $(0.7850)$ \\
\hline
\end{tabular}

Notes: p-values are shown in ( ) 


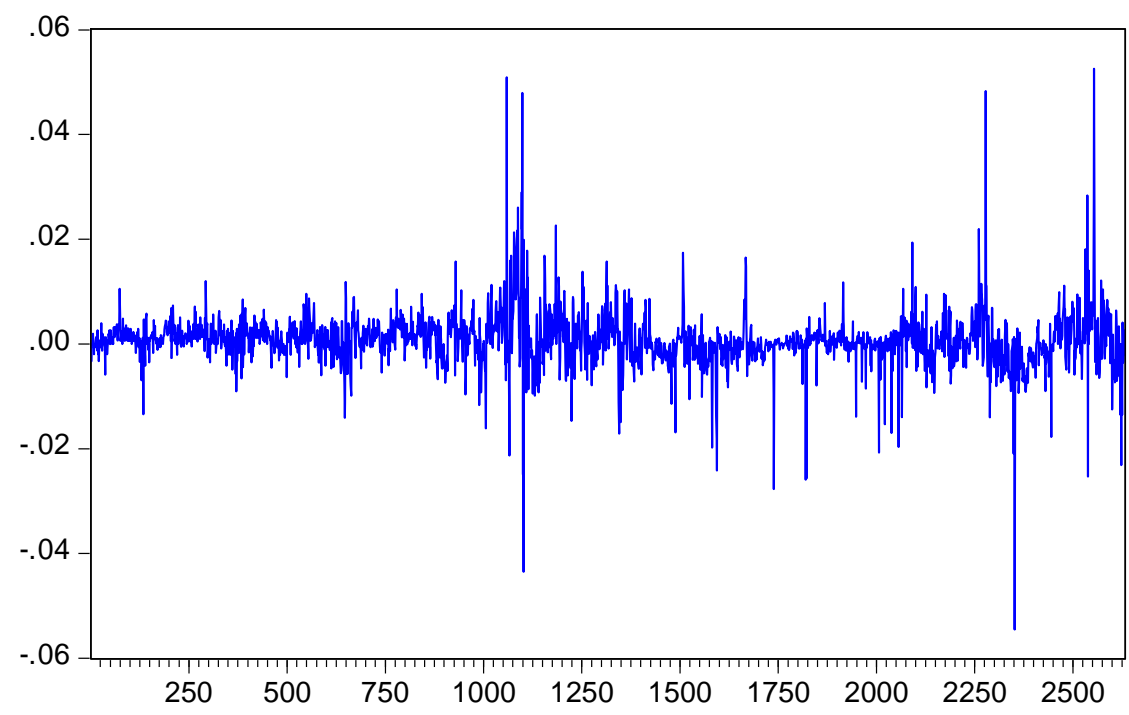

Figure 1 . The time plot of daily Iran stock returns 